\title{
Astrocytal Changes in the White Matter of Jimpy Mice: Immunohistochemistry Using Antisera to Glial Fibrillary Acidic Protein
}

\author{
Kikuko IмAмото \\ Department of Anatomy (Prof. T. Maeda), Shiga University of Medical Science, Shiga, Japan
}

Received July 3, 1985

\begin{abstract}
Summary. Immunohistochemistry using antisera to glial fibrillary acidic protein (GFAP) was performed to observe astrocytal changes in the white matter of myelin-deficient Jimpy mice.

In wild-type controls, astrocytes stained with the GFAP immunoreaction appeared in the cerebellar medulla by postnatal day 3 and in the corpus callosum by postnatal day 6 . The immunoreactivity gradually intensified with age to reach a peak of the GFAP level around postnatal day 12 . With the progress of myelinogenesis, GFAP positive astrocytes decreased in number and became sparse in the white matter.

On the other hand, the white matter of Jimpy mutant mice revealed intensified GFAP immunoreactivity, corresponding to a numerical increase in astrocytes and an enlargement of their cytoplasm. This condition continued from postnatal day 12 up to the end of life. Such astrocytes made up a dense framework with thickened processes in the non-myelinated white matter, where oligodendrocytes were few. Under the electron microscope, an accumulation of gliofilaments and glycogen particles was apparent in the enriched astrocytal cytoplasm. Immunostaining was observed not only on gliofilament bundles but also rough endoplasmic reticulum and cytoplasmic matrix.

The present results demonstrate that astrocytal hypertrophy and hyperplasia occur in the entire white matter of Jimpy mice.
\end{abstract}

Jimpy-Tabby strain mice have been first reported by PHILLIPS (1954) and are known as neurological mutants suffering from a defect of myelin sheaths in the central nervous system (Sidman, 1964; FarkAs-BARGETON et al., 1972). A recessive lethal factor in the $\mathrm{X}$-chromosome is inherited from a female carrier to male mutants, which display abnormalities such as tremors of the body axis around postnatal day 10, paralysis of hindlegs around postnatal day 20 , and finally tonic extensions and motionless postures. These mutant mice die within 25 days after birth.

In a pilot experiment, we have already noted that there were a moderate number of glioblasts capable of producing both oligodendrocytes and astrocytes in the ccrpus callosum and the subependyma of a newborn Jimpy mouse (Iмамото et al., 1983). However, oligodendrocytes never appeared in the white matter of older animals, in which astrocytes seemed to increase in number and to produce numerous gliofilaments (Iмамото, 1983). 
Recently, the glial acidic protein was isolated from fibrous astrocytes and confirmed to be a specific component of gliofilaments (ENG et al., 1971; Bignami et al., 1972). In addition, it was maintained that the glial acidic proteins of vertebrates shared common antigenic determinants with human GFAP (BIGNAMI and DAHL, 1973, 1974). Thus, rabbit antisera to human GFAP crossreacted well with the GFAP of mice and other vertebrates (BignAmi and DAHL, 1974; OnTEniEnte et al., 1983).

In order to clarify the histogenesis and differentiation of astrocytes in the white matter of Jimpy mice showing abnormal myelinogenesis, GFAP immunohistochemistry was employed in this study.

\section{MATERIALS AND METHODS}

The mating pairs, heterozygous carrier females and wild-type males of Jimpy-Tabby strain mice, were obtained from the Physiological Department of Wakayama Medical Collage (originally purchased from the Jackson Lab, Bar Harbor, Maine, USA). After continuous breeding in our animal center, Jimpy and wild-type males were chosen from littermates of various ages ranging from 1 to 25 days.

For the preparation of Epon sections, animals were perfused with a mixed aldehyde solution (2\% paraformaldehyde, $3 \%$ glutaraldehyde in $0.1 \mathrm{M}$ phosphate buffer at $\mathrm{pH}$ 7.4). The brain pieces were processed for Epon embedding by a routine method.

For GFAP immunohistochemistry, animals were perfused with a fixative composed of $4 \%$ paraformaldehyde, $0.5 \%$ glutaraldehyde and $0.2 \%$ picric acid in $0.1 \mathrm{M}$ phosphate buffer at $\mathrm{pH}$ 7.4. The whole brain was postfixed overnight in the fresh fixative and immersed in a 15\% sucrose phosphate buffer for 2 days. Sagittal and frontal sections of $20-50 \mu \mathrm{m}$ in thickness were made by a cryostat or vibratome. These sections were stocked for a few days in Triton X-PBS $(0.9 \% \mathrm{NaCl}$ in $0.1 \mathrm{M}$ phosphate buffer containing $0.05 \%$ Triton $\mathrm{X}-100$ ). The peroxidase anti-peroxidase (PAP) technique was applied to the sections (STERnBERGER et al., 1970).

The first incubation was in rabbit anti-human GFAP antisera (DAKO corp. Denmark), 1/6,000 dilution in Triton X-PBS, for 3 days at $4^{\circ} \mathrm{C}$. The second incubation was in goat anti-rabbit IgG (Miles-Yeda Ltd., Israel), 1/5,000 dilution in Triton X-PBS, for $3 \mathrm{hrs}$ at room temperature. The third incubation was in rabbit PAP (MBL Ltd., Japan), 1/5,000 dilution in Triton X-PBS, for $3 \mathrm{hrs}$ at room temperature. The immunoreaction was visualized in a solution of $0.02 \%$ diamino benzidine (DAB) and $0.015 \%$ $\mathrm{H}_{2} \mathrm{O}_{2}$ in $0.05 \mathrm{M}$ Tris buffer at $\mathrm{pH} 7.6$ for $10 \mathrm{~min}$. After each step, the floating sections were rinsed in Triton X-PBS and mounted on gelatin coated glass slides, while some sections were embedded in Epon for examination under an electron microscope.

\section{RESULTS}

In order to know the glial population in the corpus callosum, cells were counted in $0.5 \mu \mathrm{m}$ Epon sections stained with toluidine blue. In the younger animals, it was rather difficult to diagnose either Jimpy mutants or wild-type normal mice since abnormal behavior was absent. Therefore, baby mice younger than 9 days of age were not included in the glial cell counts. Results were summarized in percentages in Table 1.

Myelination normally started around 4 days after birth in the cerebellar medulla and around 7 days in the corpus callosum. Prior to the onset of myelinogenesis, 
Table 1. Percent of glial cells in an area of $0.94 \mathrm{~mm}^{2}$ of the corpus callosum

\begin{tabular}{ccccccccc}
\hline Age & $\begin{array}{l}\text { Immature } \\
\text { cells } \\
(\text { days })\end{array}$ & $\begin{array}{c}\text { Oligodendrocytes } \\
(\%)\end{array}$ & $\begin{array}{c}\text { MO } \\
(\%)\end{array}$ & $\begin{array}{c}\text { DO } \\
(\%)\end{array}$ & $\begin{array}{c}\text { Astrocytes } \\
(\%)\end{array}$ & $\begin{array}{c}\text { Microglia } \\
(\%)\end{array}$ & $\begin{array}{c}\text { Macrophages } \\
(\%)\end{array}$ & $\begin{array}{c}\text { Degenerat- } \\
\text { ing cells } \\
(\%)\end{array}$ \\
\hline $\begin{array}{c}\text { Controls } \\
9\end{array}$ & 53.3 & 11.0 & 3.3 & 0.0 & 24.0 & 2.0 & 5.4 & 1.0 \\
14 & 40.7 & 21.8 & 4.4 & 0.0 & 26.7 & 3.6 & 1.0 & 1.8 \\
21 & 19.5 & 33.9 & 9.0 & 1.5 & 29.0 & 3.5 & 2.0 & 1.6 \\
\hline Jimpy & & & & & & & & \\
9 & 55.4 & 4.9 & 0.0 & 0.0 & 25.8 & 14.2 & 5.4 & 4.3 \\
14 & 30.8 & 3.7 & 0.0 & 0.0 & 43.5 & 9.0 & 7.4 & 4.3 \\
21 & 19.5 & 2.6 & 0.0 & 0.0 & 49.3 & 7.7 & 14.6 & 6.3 \\
\hline
\end{tabular}

The number indicates the average percent of glial cells counted in the corpus callosum of five mice in each group. The cell identification depends on the criteria used in the previous report. LO, MO and DO indicate light, medium shade and dark oligodendrocytes, respectively (Iмамото et al., 1978).

A
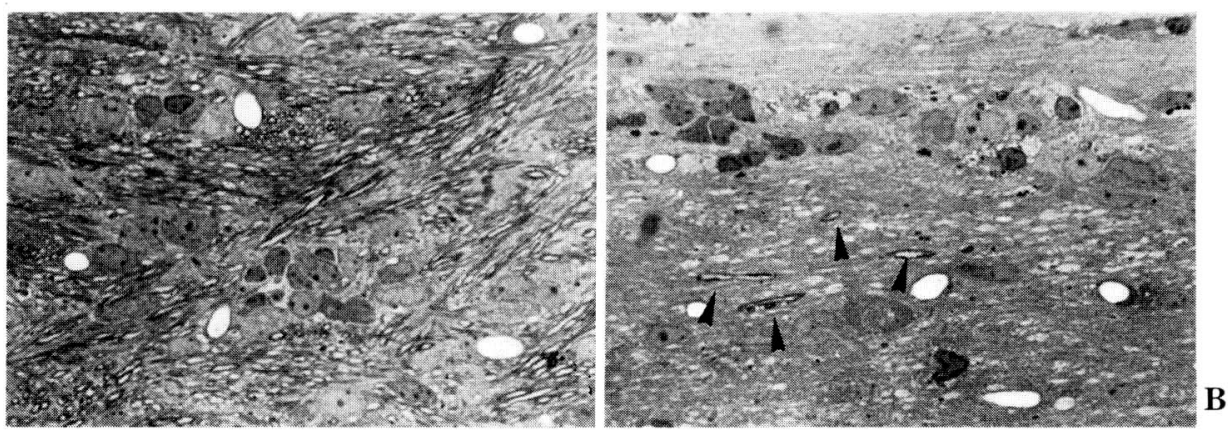

Fig. 1. Corpus callosum stained with toluidine blue. Epon embedded semithin section. A. control, B. Jimpy mutant. The corpus callosum in a wild-type control is well myelinated at 21 days after birth, while it is barely myelinated in a Jimpy mutant of the same litter. Arrowheads indcate the myelin sheaths. $\times 450$

immature glial cells acquired a large cytoplasm. In the oligodendrocyte group, a sequential cell transformation took place thereafter. Based on the stainability with toluidine blue, three subtypes of oligodendrocytes were distinguished. The pattern of cell transformation in control mice was in complete accord with previous observations in rats (Імамото et al., 1978). However, there was no maturation of oligodendrocytes in Jimpy mice, as shown in Table 1 by the peak of medium and dark oligodendrocytes. Most axons were naked in the white matter on postnatal day 21 , whereas in controls they were distinctly wrapped by myelin sheaths (Fig. 1a, b). Instead of myelinforming oligodendrocytes, there were increases in the numbers of astrocytes, degenerating cells and macrophage-like cells in the mutant mice.

Concerning astrocytes in the white matter, the cell differentiation generally started slightly earlier than that of oligodendrocytes, as shown by GFAP immunoreactivity. Morphologically, the astrocyte was characterized by a large pale nucleus with dense chromatin clumps around the nuclear membrane and the presence of gliofilaments and glycogen particles. Such morphological features were reinforced in Jimpy mutant mice as shown in Figure 2. The cytoplasmic matrix became rather dense in comparison 


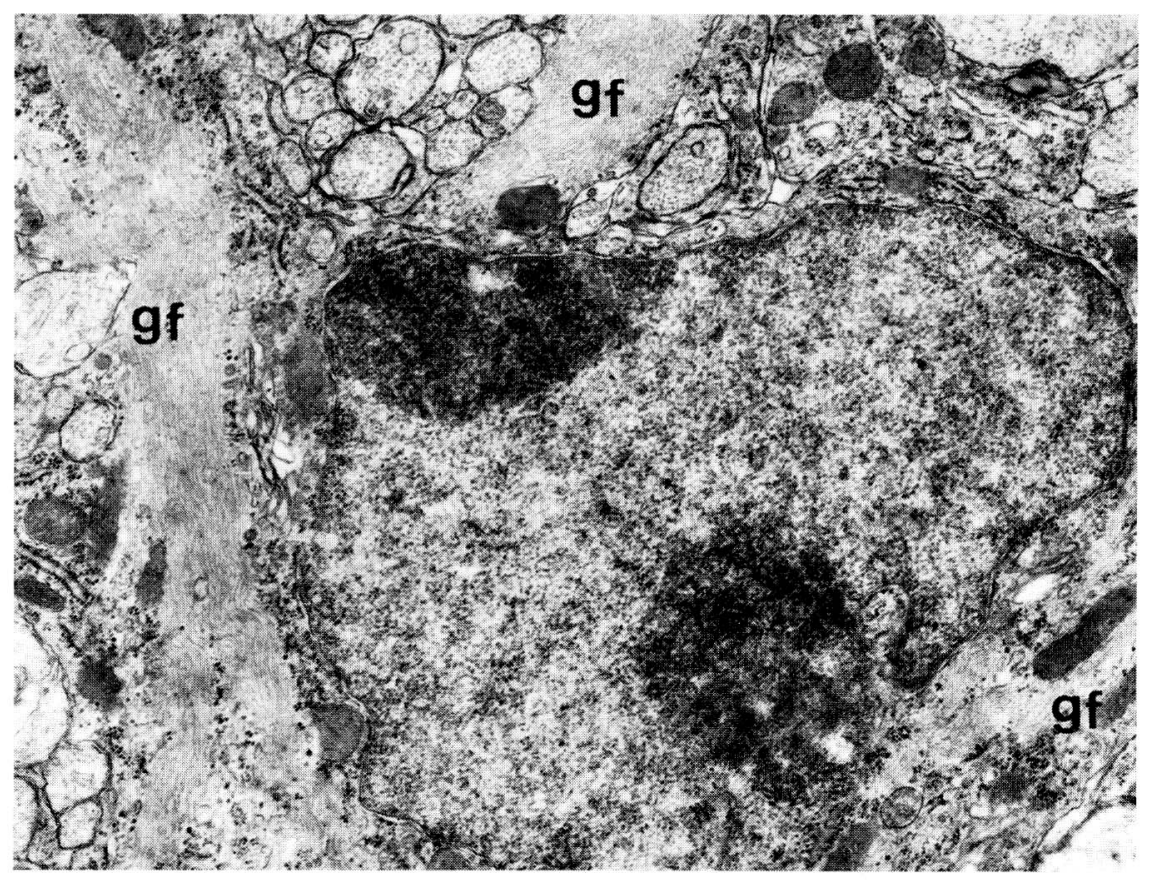

Fig. 2. Astrocyte in the white matter of a Jimpy mouse. Note an accumulation of gliofilaments $(G f)$ and glycogen particles in the rather dense cytoplasm. $\quad \times 20,000$

with the watery cytoplasm of astrocytes in controls. In Jimpy mice, astrocytes formed about half of the glial population in the corpus callosum at 21 days instead of $29 \%$ in controls (Table 1 ).

\section{GFAP immunohistochemistry}

In general, GFAP immunoreactivity in astrocytes was intensified in the course of differentiation or cell maturation. The radial glial cells and the fibers were also reactive. Under the electron microscope, it was confirmed that the reaction products deposited not only on the gliofilament bundles but also on the rough endoplasmic reticulum and the cytoplasmic matrix of the enriched astrocyte (Fig. 3).

\section{Radial glial cells and fibers}

In the newborn period, GFAP positive elements were barely found in the brain parenchyma in either the wild-type or Jimpy mutant mice. Within the first few days of life, the radial glial cells and the fibers in the ependymal zone acquired a distinct immunoreaction. The projection of the long processes from the ependyma toward the pial surface was often noted in certain parts around ventricles. The most radial cells, however, gradually showed reduced immunoreactivity as the maturation of the brain parenchyma proceeded. Thus, it became rather difficult to identify them after postnatal day 10. Nevertheless, some specific radial fibers such as Bergmann's fibers and the radial fibers in the circumventricular organs retained the ability to immunostain in the adults. 


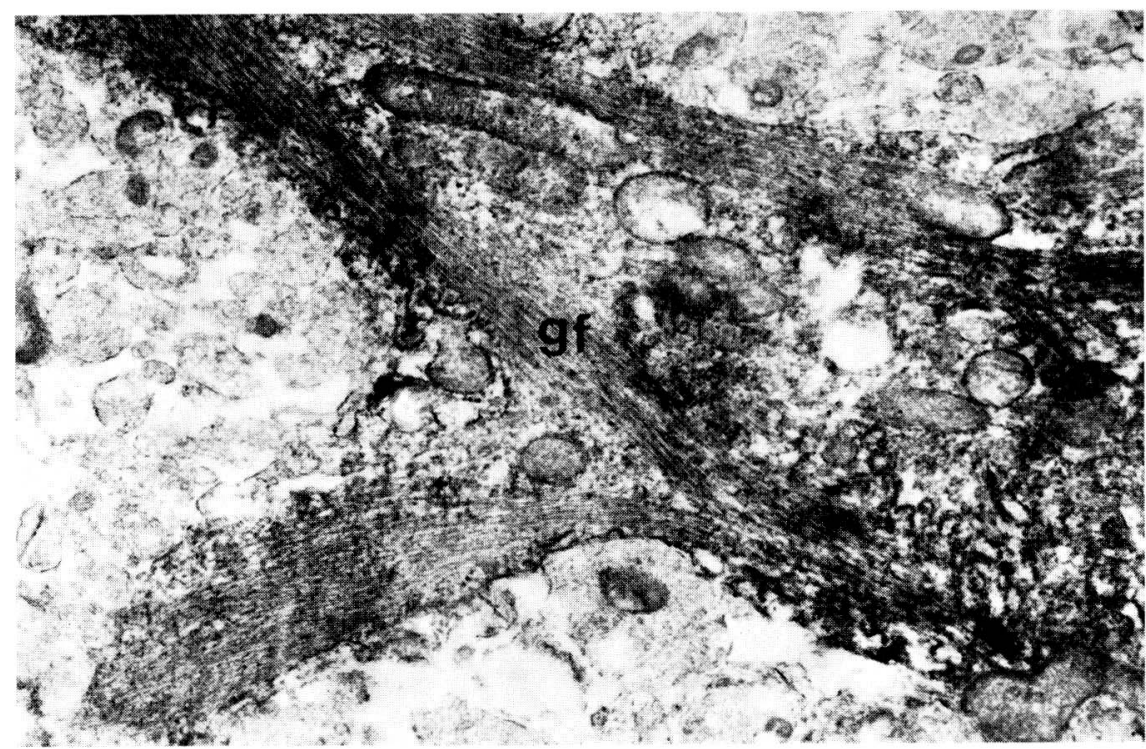

Fig. 3. Electron micrograph of a GFAP positive astrocyte in the white matter of a Jimpy mouse at 14 days after birth. By the reaction products, the electron density of gliofilaments $(G f)$ and the cytoplasmic matrix was rather high. $\times 17,000$

A
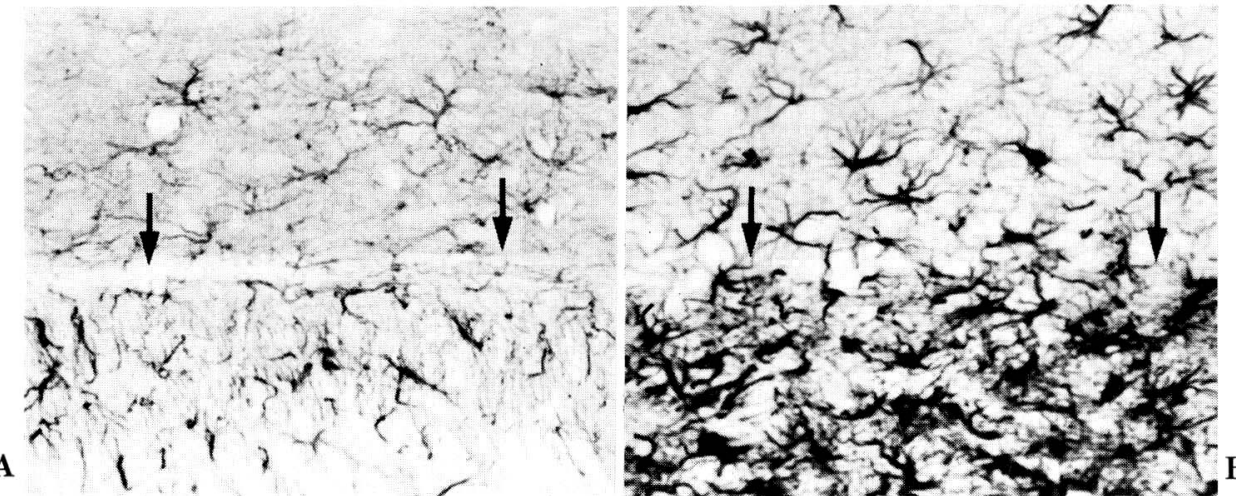

Fig. 4. GFAP immunoreaction in the corpus callosum at 21 days after birth. A. control, B. Jimpy. In the control, astrocytes with thin processes are scattered in the cerebral cortex and in the corpus callosum, whereas those in a Jimpy mutant indicate a intensified GFAP immunoreaction. Arrows indicate the border between the cerebral cortex and the corpus callosum. $\times 250$

\section{Astrocytes in the white matter}

In the newborn, there was no typical astrocyte reacting with GFAP antisera in the corpus callosum and other areas of white matter. On postnatal day 3, GFAP positive cells regarded as fibrous astrocytes appeared in the regions of the future white matter in the rhombencephalon, such as the cerebellar medulla and peduncles, and the pyramidal tract. On postnatal day 6 , astrocytes showing GFAP immunoreactivity arose in the white matter areas of the telencephalon, such as the corpus callosum, anterior commissure and internal capsule. Astrocytes in the telencephalon acquired immunoreactivity a few days later than those in the rhombencephalon. By postnatal day 12, 


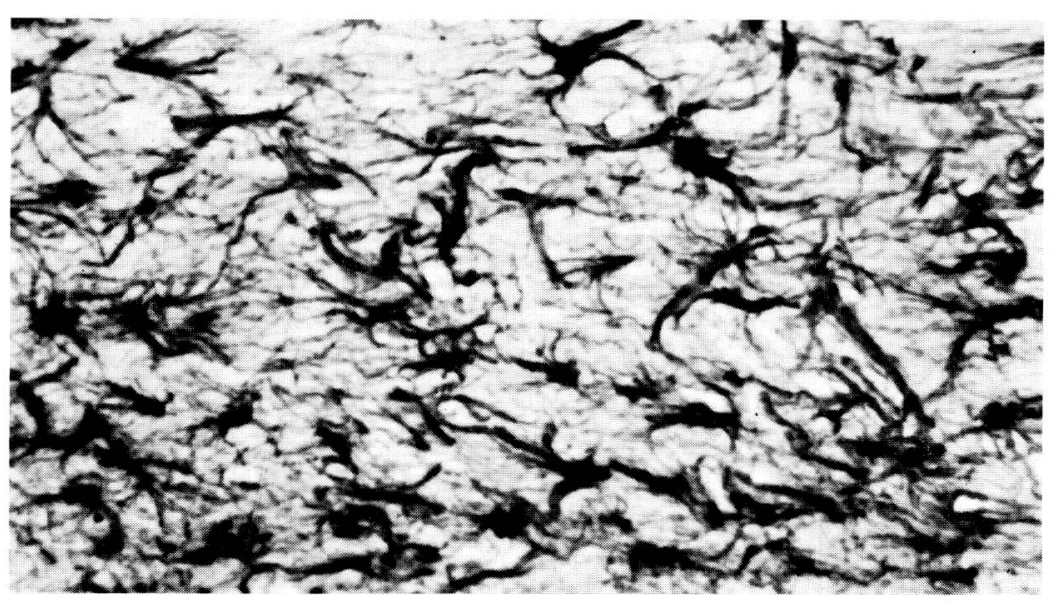

Fig. 5. GFAP immunoreaction in the corpus callosum of a Jimpy mutant at 23 days after birth. Note the distinct framework of the thickened astrocytal processes. $\times 450$

immunoreactivity increased enough to visualize the astrocytal framework both in wild-type controls and the Jimpy mice. At this period, the GFAP immunoreaction of astrocytes reached its maximal level in controls. Thereafter, with the progress of myelinogenesis in the white matter of the control, the astrocytal framework became rather indistinct.

In the meantime, the GFAP immunoreactivity in the Jimpy mice continued to increase until the end of life, i.e., about 25 days after birth (Fig. 5). The enhancement of the immunoreactivity was likely activated by the myelin deficiency. As the supporting tissue among the non-myelinated white matter, astrocytes seemed to expand their thick processes. Incidentally, the numerical increase in astrocytes was clearcut in Jimpy mice (Table 1 ).

As a matter of fact, differences in GFAP immunoreactivity between wild-type controls and Jimpy mice was characteristically noted in the cerebellar medulla (Fig. 6). Nevertheless, astrocytes located in the main parts of the neocortex indicated no particular alteration during postnatal development, although some astrocytes in the fifth and sixth layers showed an intensified GFAP immunoreaction.

\section{DISCUSSION}

In our experience, the immature cells destined for the oligodendrocyte line never matured in the mutant mice. The cell transformation from the glioblasts to light, medium and finally dark oligodendrocytes was described as an essential event during myelinogenesis in the corpus callosum of rats (Імамото et al., 1978). The absence of mature oligodendrocytes implied some interference with differentiation. The defect of myelin sheaths was known to be due to an absence of mature myelin-forming oligodendrocytes (FARKAS-BARGETON et al., 1972) rather than to a breakdown of the myelin lamella or to demyelination (Sidman, 1964). The reason why immature oligodendrocytes never grew up to mature types remained uncertain. One possibility was introduced in the last paragraph of Discussion.

The GFAP immunohistochemistry is useful for the study of cell properties in the 


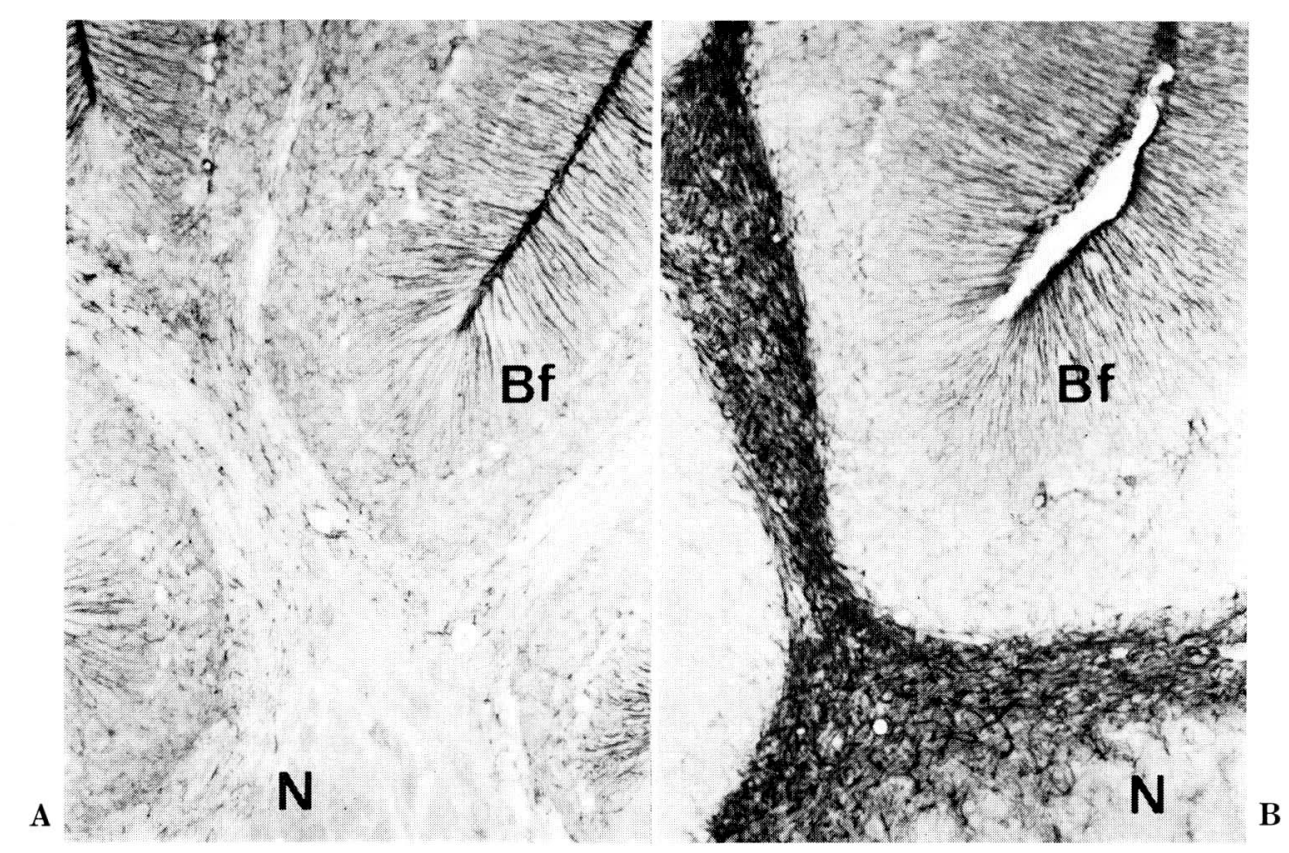

Fig. 6. GFAP immunoreaction in the cerebellum in a Jimpy mutant at 21 days after birth. A. control, B. Jimpy mutant. The cerebellar medulla in the Jimpy mouse displays intensified GFAP immunoreactivity. Bergmann's fibers ( $B f)$ in the cerebellar cortex show a quite similar immunoreactivity both in Jimpy and control mice. $\times 120$

astrocytal group. Besides typical astrocytes, the radial glial cells and the fibers reacted well with GFAP antisera. This fact might provide a significant advantage to redefine cell properties and their interrelations in the developing brain. However, we focused our attention on the fibrous astrocytes in the white matter.

Our immunohistochemical data coincided with biochemical findings that the GFAP level normally increased during early myelinogenesis; then it gradually decreased and finally remained at a constant low level for a long period, whereas the GFAP level in Jimpy mice kept on increasing until death (JACQUE et al., 1976, 1980).

Astrocytes in the white matter acquired the GFAP immunoreactivity during the early postnatal development. In newborn mice, the only GFAP positive elements were radial glial cells and the fibers. Thus, it was clear that most astrocytes started to differentiate after birth. As far as we have examined, it is rather hard to say whether typical astrocytes evolve from the radial glial cells. Prior to myelin formation, astrocytes might have an important role to support non-myelinated axons. Similarly, astrocytal hypertrophy and hyperplasia in Jimpy mice might be caused as the result of reinforcement of the supporting tissue. As the secondary change in the myelindeficient white matter, the astrocyte framework expanded. There was a little possibility that the hypertrophy and hyperplasia of astrocytes prevented oligodendrocytes from wrapping their processes around axon cylinders. However, it was confirmed that astrocytes actively increased in number in controls before myelin formation started. Thus, it was difficult to consider that the astrocytal changes in Jimpy mice were the cause of the interference with the differentiation of oligodendrocytes.

Recently, myelin basic protein and other myelin components have been considered 
to be antigens capable of inducing experimental allergic encephalitis (EYLAR, 1978; Hashim, 1978; Moor et al., 1984). According to Mokhtarian et al. (1984), T-cells sensitized by the myelin basic protein produced a chronic relapsing demyelinating disease in mice. Therefore, it was possible that the autoimmune disease was mediated by T-cells (EYLAR, 1978; Agrawal et al., 1984). An accumulation of myelin components into the plasma membrane of oligodendrocytes might cause the autoimmune response. Further experiments are needed to confirm this possibility.

Acknowledgements. The author is grateful to Dr. N. Shimizu and Dr. C. P. Leblond for their kindness in reading this manuscript and to Miss A. TAmURA for her technical assistance. Thanks are also due to the Physiological Department of Wakayama Medical College for providing animals.

\section{REFERENCES}

Argawal, H. C., H. B. Clark, D. Agrawal, F. J. Seil and H. Quarles: Identification of antibodies in anti-CNS and anti-PNS myelin sera by immunoblot, characterization by immunohistochemistry, and their effect in tissue culture. Brain Res. 307: 191-200 (1984).

Bignami, A. and D. Dahl: Astrocyte-specific protein and neuroglial differentiation. An immunofluorescence study with antibodies to the glial fibrillary acidic protein. J. comp. Neurol. 153: 27-38 (1974).

- : Differentiation of astrocytes in the cerebellar cortex and the pyramidal tracts of the newborn rat. An immunofluorescence study with antibodies to a protein specific to astrocytes. Brain Res. 49: 393-402 (1973).

Bignami, A., L. F. Eng, D. Dahl and C. T. Uyeda: Localization of glial fibrillary acidic protein in astrocytes by immunofluorescence. Brain Res. 43: 429-435 (1972).

Eng, L. F., J. J. Vanderhaegen, A. Bignami and B. Gerstl : An acidic protein isolated from fibrous astrocytes. Brain Res. 28: 351-354 (1971).

Eylar, E. H.: Peptides and autoimmune disease. Adv. exp. Med. Biol. 98: 259-281 (1978).

Farkas-Bargeton, E., O. Robain and P. Mandel: Abnormal glial maturation in the white matter in Jimpy mice. An optical study. Acta neuropathol. (Berl.) 21: 272-281 (1972).

Hashim, G. A.: Myelin basic protein: Structure, function and antigenic determinants. Immunol. Rev. 39: 60-107 (1978).

Imamoto, K.: Gliogenesis in the mutant Jimpy mice (Abstract). Acta anat. nippon. 58 : 287 (1983).

Imamoto, K., H. Imai and T. Maeda: Morphological alterations in the astrocytes observed in the myelin systhesis defficiency mice (Abstract). Acta anat. nippon. 58: 189 (1983).

Imamoto, K., J. A. Paterson and C. P. Leblond: Radioautographic investigation of gliogenesis in the corpus callosum of young rats. 1. Sequential changes in oligodendrocytes. J. comp. Neurol. 180: 115-138 (1978).

Jacque, C. M., O. S. Jorgensen, N. A. Baumann and E. Bock: Brain specific antigens in the quaking mouse during ontogeny. J. Neurochem. 27: 905-909 (1976).

Jacque, C., F. Lachapelle, P. Collier, M. Raoul and N. Baumann: Accumulation of GFA, the monomeric precursor of the gliofilaments, during development in normal mice and dysmyelinating mutants. J. Neurosci. Res. 5: 379-385 (1980).

Mokhtarian, F., D. E. McFarlin and C. S. Raine: Adoptive transfer of myelin basic protein sensitized cells produces chronic relapsing demyelinating desease in mice. Nature 309: 356-358 (1984).

Moore, G. R. W., U. Traugott, M. Farooq, W. T. Norton and C. S. Raine: Experimental autoimmune encephalomyelitis augmentation of demyelination by different myelin lipids. Lab. Invest. 51: 416-424 (1984). 
Onteniente, B., H. Kimura and T. Maeda : Comparative study of the glial fibrillary acidic protein in vertebrates by PAP immunohistochemistry. J. comp. Neurol. 215: 427-436 (1983).

Phillips, R. J. S.: Jimpy, a new totally sex-linked gene in the house mouse. Z. indukt. Abstamm.Vererb.-Lehre 86: 322-326 (1954).

Sidman, R. L.: Mutant mice (Quaking and Jimpy) with deficient myelination in the central nervous system. Science 144: 309-311 (1964).

Sternberger, L. A., P. H. Hardy, J. J. Cuculis and H. G. Mayer: The unlabelled antibody enzyme method of immunohistochemistry. J. Histochem. Cytochem. 18: 315-333 (1970).

今本喜久子

厂520-21 大津市瀬田月輪町

滋賀医科大学

解剖学第一教室
Dr. Kikuko Iмамото

Department of Anatomy

Shiga University of Medical Science

Seta-Tsukinowa, Ohtsu, Shiga

520-21 Japan 